\title{
APPLICATION OF PRINCIPAL COMPONENT ANALYSIS TO DROUGHT INDICATORS OF THREE REPRESENTATIVE CROATIAN REGIONS
}

Scientific paper

Lidija Tadić

(Received: 19 May 2021; accepted: 28 June 2021) Josip Juraj Strossmayer University of Osijek, Faculty of Civil Engineering and Architecture Osijek, Prof. Corresponding author: Itadic@gfos.hr

\section{Tamara Brleković} Josip Juraj Strossmayer University of Osijek, Faculty of Civil Engineering and Architecture Osijek, Assist. Prof.

Kristina Potočki

University of Zagreb, Faculty of Civil Engineering, Assist. Prof.

Marija Leko-Kos

Insitute IGH, Osijek, dr.sc.

\begin{abstract}
Drought has become a very frequent hydrological event globally, including in Croatia. It can generally be explained by air temperature and precipitation changes on an annual and seasonal basis, owing to climate change. To contribute to the knowledge on drought phenomena in Croatia, the changes in air temperature and precipitation over a relatively long period between 1951 and 2018 were analyzed. The meteorological stations included in the research were Osijek, Zagreb, and Split, which represented the climate of the entire country. Drought was estimated using the standardized precipitation evapotranspiration index, which is one of the most comprehensive drought indices. Furthermore, the drought severity and duration were calculated using run theory. These parameters were tested for homogeneity using the standard normal homogeneity test. Only the air temperature exhibited inhomogeneity, with a break year in 1991 (Zagreb and Split) and 1998 (Osijek). The existence of significant temporal trends was tested using the non-parametric Mann-Kendall trend test. The probability of drought occurrence with a certain duration and severity was calculated using the copula function. Finally, principal component analysis was applied to the computed standardized Mann-Kendall test statistic $\left(Z_{\mathrm{MK}}\right)$ to define the relevance of each parameter change and their combination in drought occurrence on a seasonal basis. Drought occurrence was less recognizable from 1951 to 1991 (1998). In the second sub-period, the impact of an increasing air temperature was the most significant variable, particularly in Zagreb.
\end{abstract}

Key words: Drought; SNHT; PCA; copula function. 


\section{INTRODUCTION}

Drought occurrence has been the subject of numerous studies globally, including in Croatia. The first papers on drought occurrence and its severity were published in the early 90s [1]. It is a complex physical process that depends on physical catchment characteristics (land cover, soil type, and geological structure) and hydroclimatic conditions (temperature and precipitation), and the recognition, description, and prediction of drought is not a simple task [2]. A frequently asked question is: When did droughts start to become so frequent? One responsible process is the increase in the air temperature. In Croatia, statistically significant changes in the mean annual temperature first occurred in 1988 and in 1992 [3]. However, seasonal changes are usually more important and stressful when analyzing water requirements in agriculture. Moreover, the increasing trends of air temperature are not the only factors responsible for climate change impact. Changes in precipitation regimes cannot be neglected. One well-known method for drought estimation is based on precipitation data, namely the standardized precipitation index (SPI) [4]. In recent years, it has been modified by introducing air temperature indirectly via evapotranspiration, resulting in the standardized precipitation evapotranspiration index (SPEI) [5]. This method was used in a study on the changes in the drought occurrence, frequency, and severity in Europe. The results confirmed that the entire European continent, with the exception of Iceland, will be affected by more frequent and severe extreme droughts, particularly after 2070 [6]. On a seasonal basis, drought will increase in summer and autumn, especially in southern and eastern Europe [7]. Moreover, research on drought in western Europe demonstrated that in this region, climate variability is more dominant than long-term trends [8]. Therefore, the main task of this research was to provide an additional perspective on drought problems by using principal component analysis (PCA), which combines several variables that are essential for drought description and provides the most dominant drought characteristics.

\section{MATERIALS AND METHODS}

\subsection{Study area}

The research on drought severity in Croatia was focused on data series obtained from three meteorological stations: Osijek, Zagreb, and Split (Figure 1). According to the Köppen classification of climate zones, Osijek and Zagreb belong to the temperate humid climate with warm summers ( $\mathrm{Cfb}$ ), whereas Split belongs to the Mediterranean climate with hot summers (Csa) [9]. Although Osijek and Zagreb belong to the same climate zone, they are in different orographic regions. Osijek is in the eastern mainland and Zagreb is in the western mainland. In the reference period between 1961 and 1990, the annual precipitation of Osijek was $733 \mathrm{~mm}$ and that of Zagreb was $923 \mathrm{~mm}$ [10]. According to the aridity index, Osijek is substantially more vulnerable to drought [11]. 


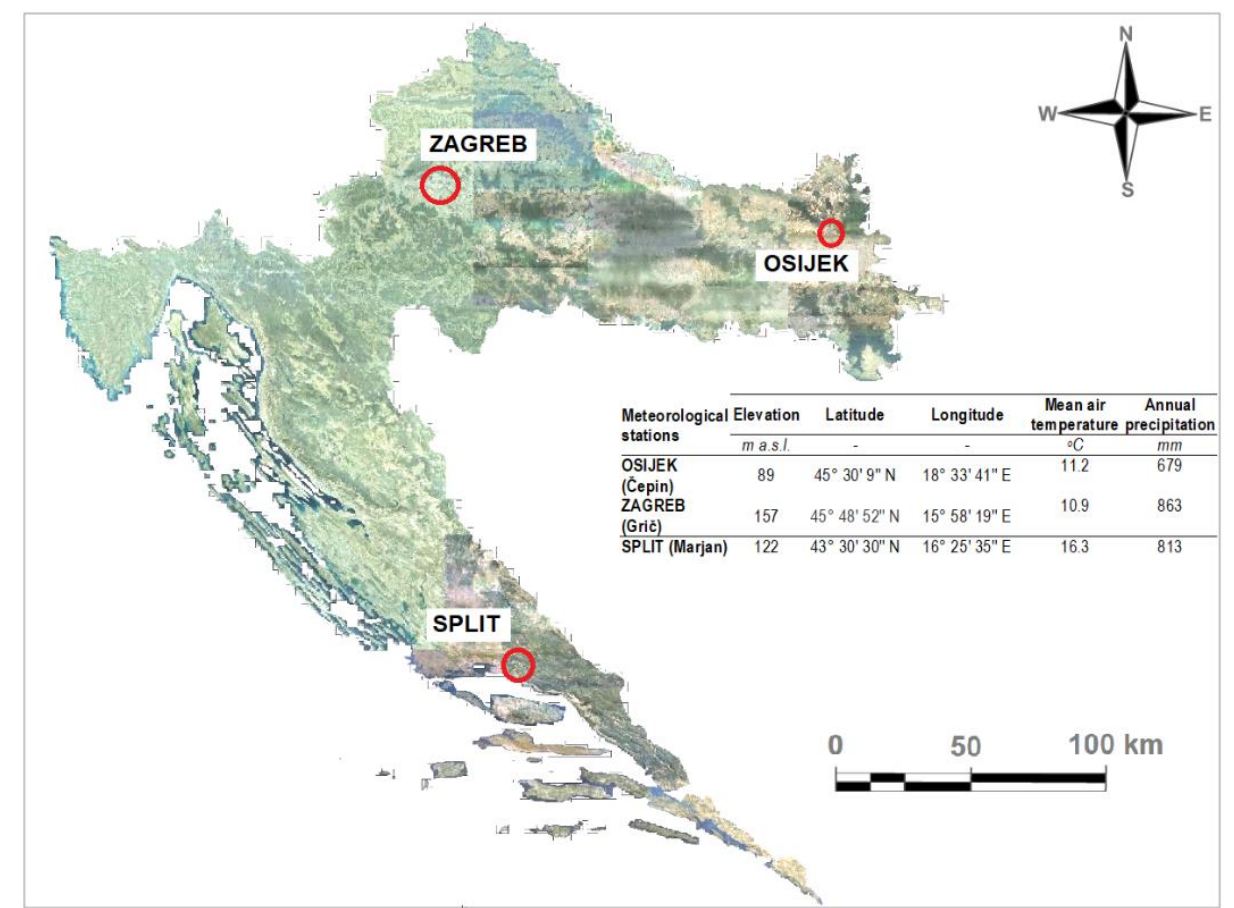

Figure 1 Study area with basic data of meteorological stations, and mean air temperature and precipitation sum for analyzed period (1951 to 2018)

All analyses and calculations were performed on the basis of the same monthly data series of 68 years (1951 to 2018).

\subsection{SPEI}

Previously published research on drought, based on data series from 13 meteorological stations, confirmed that the most appropriate drought index for Croatian meteorological conditions is the SPEI, owing to the potentially significant influence of temporal changes in the air temperature on the water deficiency [12]. The SPEI is an integrated drought index, which considers precipitation and evapotranspiration, and is more conclusive than indices based only on temperature and precipitation [13,14]. The SPEI was proposed by Vicente-Serrano [5] and can be used on different time scales. The potential evapotranspiration was calculated using the Thornthwaite equation. The time scale of the SPEI analysis was one month and calculations were performed for the Osijek, Zagreb, and Split meteorological stations, as shown in Figure 2. The designated limit values are provided according to the classification presented in Table 1. 


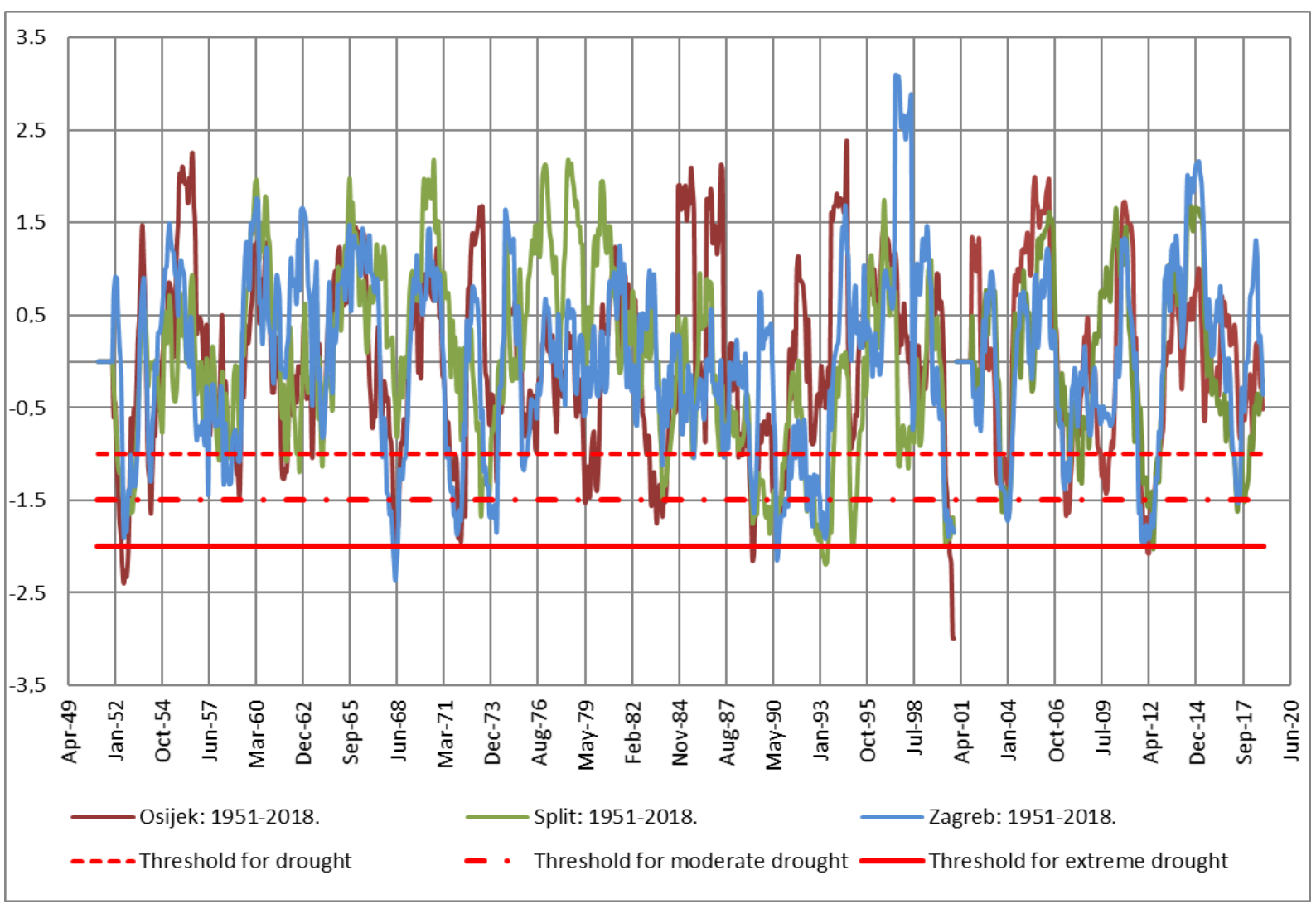

Figure 2 One-month SPEI values for Osijek, Zagreb, and Osijek meteorological stations in the observed period (1951 to 2018)

The SPEI data series were homogeneous as examined by standard normal homogeneity.

Table 1 Limit values for SPEI [5,15]

\begin{tabular}{cc}
\hline SPEI & SPEI classification \\
\hline$\geq 2.00$ & Extremely wet \\
$1.50-1.99$ & Very wet \\
$1.00-1.49$ & Moderately wet \\
$-0.99-0.99$ & Normal \\
$-1.49-(-1.0)$ & Moderately dry \\
$-1.99-(-1.5)$ & Very dry \\
\hline
\end{tabular}

\subsection{Standard normal homogeneity test}

The standard normal homogeneity test (SNHT) is one of the most commonly used test tools for the confirmation of data homogeneity. It was developed by Alexandersson (1986) and has been applied to a precipitation dataset from southwestern Sweden [16]. In recent years, it has been very useful for the detection of change points in climate-related hydrological and meteorological data or statistical parameters, such as data variabilities [17]. The test statistic $T(y)$ is used to compare the mean of the first $y$ observations with the mean of the remaining $(n-y)$ observations with $\mathrm{n}$ data points. It can be written as:

$T y=y \overline{z 1}+(n-y) \overline{z 2} y=1,2, \ldots n$

Where:

$\overline{z 1}=\frac{1}{n} \sum_{i=1}^{n} \frac{(Y i-\bar{Y})}{s}$ and $\overline{z 2}=\frac{1}{n-y} \sum_{i=y+1}^{n} \frac{(Y i-\bar{Y})}{s}$

Tadić, L, Brleković, T, Potočki, K, Leko-Kos, M 
Application of principal component analysis to drought indicators of three representative Croatian regions

If the value of T exceeds the maximum value, year $y$ is the break year of the data series $[18,19]$.

All data series that were relevant to this research were tested using the SNHT. On a monthly basis, the air temperature exhibited consistent inhomogeneity with significantly higher air temperatures in the second subperiod. In Zagreb and Split, the break year was in 1991, and that in Osijek was several years later, in 1998 (Figure 3). The data series of the one-month SPEI values were homogeneous for the Osijek meteorological station and inhomogeneous for Zagreb, with a break year in 2013, demonstrating that the second sub-period was less dry. The Split meteorological stations also exhibited inhomogeneous SPEI values with a break year in 1983, but in this case, the second sub-period was drier than the first one. The homogeneity of the precipitation and air temperature was also tested on a seasonal basis. The precipitation was homogeneous across all seasons and stations. The air temperatures were inhomogeneous, except in the winters of Osijek and Split.

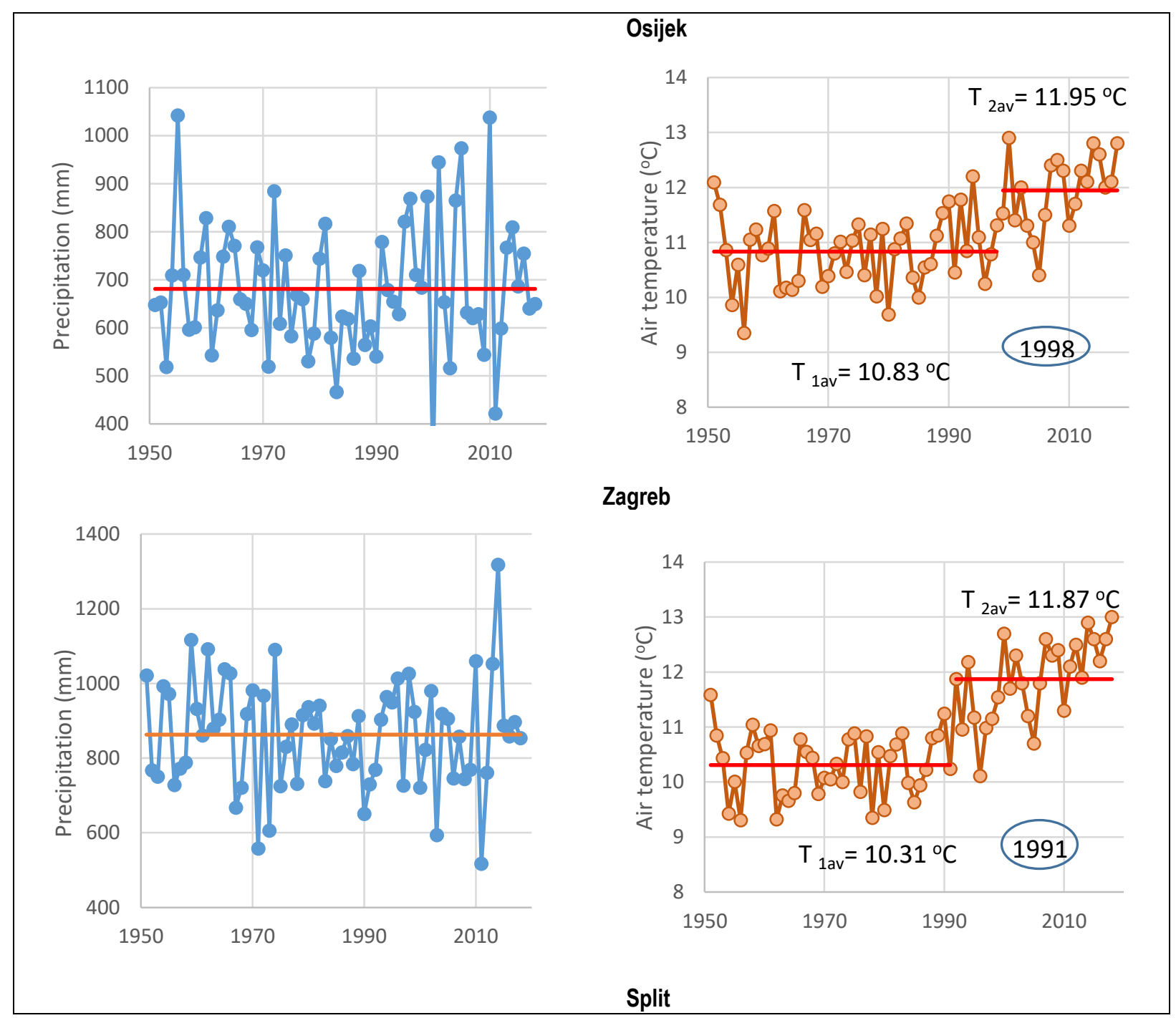

Tadić, L, Brleković, T, Potočki, K, Leko-Kos, M 


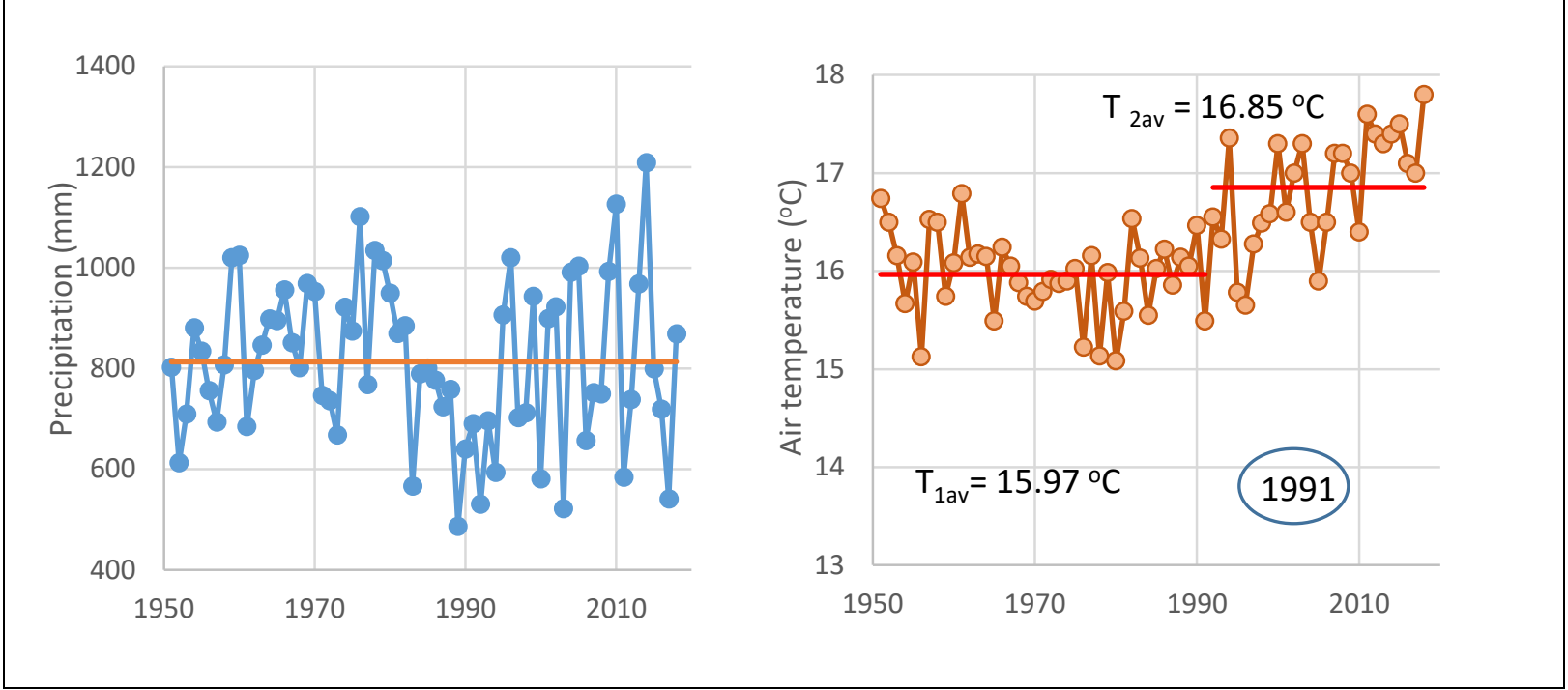

Figure 3 Results of SNHT test applied to monthly precipitation and air temperature data

\subsection{Mann-Kenndal test}

The well-known Mann-Kendall non-parametric test was applied to determine the existence of significant temporal tendencies in the indicator values $[20,21,22,23]$. The test statistic $Z_{\text {MK }}$ is described as:

$$
Z_{M K}=\left\{\begin{array}{l}
\frac{S-1}{\sigma} \text { if } S>0 \\
0 \text { if } \mathrm{S}=0 \\
\frac{S+1}{\sigma} \text { if } \mathrm{S}<0
\end{array}\right\}
$$

Where the positive and negative values indicate increasing and decreasing trends, respectively, for the period considered.

The input data presented in Table 2 consisted of $Z_{M K}$ values that were calculated for the seasonal precipitation data, seasonal air temperatures, and SPEI. They had different levels of significance, designated by the following symbols: ${ }^{* * *}$ if trend at $\alpha=0.001$ level of significance; ${ }^{* *}$ if trend at $\alpha=0.01$ level of significance; ${ }^{*}$ if trend at $\alpha=0.05$ level of significance; ${ }^{+}$if trend at $\alpha=0.1$ level of significance [24].

The test was performed for two sub-periods defined by the SNHT applied to the air temperature data series, namely 1951 to 1998 and 1999 to 2018 for the Osijek station, and 1951 to 1991 and 1992 to 2018 for the Split and Zagreb stations (Figure 1).

Table 2 Mann-Kendal trend test statistics $\mathrm{Z}_{\mathrm{MK}}$

\begin{tabular}{lccc}
\hline Osijek 1951 to 1998 & SPEI & Precipitation & Air temperature \\
& $Z_{M K}$ & $Z_{M K}$ & $Z_{M K}$ \\
\hline Spring & 0.422 & $-1.662^{+}$ & 1.378 \\
Summer & 0.367 & -0.613 & 0.702 \\
Autumn & 0.110 & $\mathbf{2 . 6 4 0} * *$ & -1.236 \\
Winter & 0.844 & -1.626 & 0.622 \\
\hline Osijek 1999 to 2018 & SPEI & Precipitation & Air temperature \\
& $Z_{M K}$ & $Z_{M K}$ & $Z_{M K}$ \\
\hline Spring & -0.350 & 0.162 & 0.195 \\
Summer & -0.210 & -0.227 & $1.753^{+}$ \\
Autumn & 0.001 & -0.681 & 0.974 \\
Winter & 0.140 & 1.460 & 1.265 \\
\hline
\end{tabular}

Tadić, L, Brleković, T, Potočki, K, Leko-Kos, M 
Application of principal component analysis to drought indicators of three representative Croatian regions

\begin{tabular}{|c|c|c|c|}
\hline Zagreb 1951 to 1991 & $\begin{array}{l}\text { SPEI } \\
Z_{M K}\end{array}$ & $\begin{array}{c}\text { Precipitation } \\
Z_{M K}\end{array}$ & $\begin{array}{c}\text { Air temperature } \\
Z_{M K}\end{array}$ \\
\hline Spring & -1.153 & -1.067 & 0.708 \\
\hline Summer & $-1.769+$ & -1.044 & -0.168 \\
\hline Autumn & -1.293 & -0.292 & -1.044 \\
\hline Winter & -1.619 & $-1.685^{+}$ & 0.348 \\
\hline Zagreb 1992 to 2018 & $\begin{array}{l}\text { SPEI } \\
Z_{M K}\end{array}$ & $\begin{array}{c}\text { Precipitation } \\
Z_{M K}\end{array}$ & $\begin{array}{c}\text { Air temperature } \\
Z_{M K}\end{array}$ \\
\hline$\overline{\text { Spring }}$ & 0.375 & 0.375 & 2.232 * \\
\hline Summer & 0.709 & -0.417 & 2.940 ** \\
\hline Autumn & -0.167 & 0.042 & 2.566 * \\
\hline Winter & -0.042 & 1.063 & 0.792 \\
\hline Split 1951 to 1991 & $\begin{array}{c}\text { SPEI } \\
Z_{M K}\end{array}$ & $\begin{array}{c}\text { Precipitation } \\
Z_{M K} \\
\end{array}$ & $\begin{array}{c}\text { Air temperature } \\
Z_{M K} \\
\end{array}$ \\
\hline Spring & -0.245 & 0.719 & -0.157 \\
\hline Summer & -0.734 & -0.809 & -0.854 \\
\hline Autumn & -0.664 & -0.168 & -0.921 \\
\hline Winter & -0.594 & -1.606 & -0.483 \\
\hline Split 1992 to 2018 & $\begin{array}{l}\text { SPEI } \\
Z_{M K}\end{array}$ & $\begin{array}{c}\text { Precipitation } \\
Z_{M K}\end{array}$ & $\begin{array}{c}\text { Air temperature } \\
Z_{M K}\end{array}$ \\
\hline Spring & 1.058 & $1.793^{+}$ & 2.252 * \\
\hline Summer & 1.058 & -0.083 & $2.273^{*}$ \\
\hline Autumn & 1.278 & -0.042 & $1.919+$ \\
\hline Winter & 1.014 & 0.917 & 0.918 \\
\hline
\end{tabular}

The precipitation trends for all three stations in the first period did not exhibit particular significance, except for their decreasing trend in spring and increasing trend in Osijek, decreasing trend in winter in Zagreb, and increasing precipitation trend in Split in spring. The SPEI had a significant negative trend in Zagreb during the summer period, which indicated an increase in drought conditions. In other regions, the SPEI, as a measure of drought, did not exhibit significant changes. In the second sub-period, there were no significant trends of the precipitation and SPEI at all, but the air temperature exhibited an increasing trend in the summer period in Osijek and particularly in spring, summer, and autumn in Zagreb and Split.

\subsection{Copula function}

Drought is usually characterized by its duration (generally expressed in months) and severity (expressed in millimeters of water deficit related to the long-term average value of precipitation), which was defined by run theory in this case. The probability of drought occurrence with a certain duration and severity was calculated using the copula function. The copula function is a successful tool for defining the joint cumulative distribution function of two or more variables. It can construct a joint distribution among multiple variables without considering the type of univariate marginal distribution, and it can combine the joint cumulative distribution function with the marginal distribution function of the variables [25].

In this case, the duration and severity were the selected variables expressed by their combinations: a) a drought duration of 0 to 3 months and SPEI sum between 0 and (-2), designated as mild drought; b) a drought duration of 0 to 3 months and SPEI sum between (-2) and (-4), designated as moderate drought; and c) a drought duration of 0 to 3 months and SPEI sum of $<(-4)$, designated as extreme drought. An analysis is provided for the two previously defined sub-periods. The proportions of dry years, which were characterized as mild, moderate or extreme, are presented in Table 3.

Table 3 Relative frequencies of years with mild, moderate or extreme drought in each sub-period

\begin{tabular}{cccc}
\hline $\begin{array}{c}\text { Osijek } \\
1951 \text { to } 1998\end{array}$ & $\begin{array}{c}\text { Duration/severity } \\
\text { - mild }\end{array}$ & $\begin{array}{c}\text { Duration/severity } \\
\text { - moderate }\end{array}$ & $\begin{array}{c}\text { Duration/severity } \\
\text { - extreme } \\
-\end{array}$ \\
\hline Spring & 0.298 & - & - \\
\hline
\end{tabular}

Tadić, L, Brleković, T, Potočki, K, Leko-Kos, M 
Application of principal component analysis to drought indicators of three representative Croatian regions

\begin{tabular}{|c|c|c|c|}
\hline Summer & 0.319 & 0.106 & 0.085 \\
\hline Autumn & 0.340 & 0.149 & 0.085 \\
\hline Winter & 0.319 & 0.149 & 0.064 \\
\hline $\begin{array}{c}\text { Osijek } \\
1999 \text { to } 2018\end{array}$ & $\begin{array}{c}\text { Duration/severity } \\
\text { - mild } \\
\text { - }\end{array}$ & $\begin{array}{c}\text { Duration/severity } \\
\text { - moderate }\end{array}$ & $\begin{array}{c}\text { Duration/severity } \\
\text { - extreme } \\
\text { - }\end{array}$ \\
\hline Spring & 0.158 & 0.211 & 0.105 \\
\hline Summer & 0.158 & 0.106 & 0.158 \\
\hline Autumn & 0.421 & 0.106 & 0.053 \\
\hline Winter & 0.368 & 0.158 & 0.053 \\
\hline $\begin{array}{c}\text { Zagreb } \\
1951 \text { to } 1991\end{array}$ & $\begin{array}{c}\text { Duration/severity } \\
\text { - mild } \\
\text { - }\end{array}$ & $\begin{array}{l}\text { Duration/severity } \\
\text { - moderate }\end{array}$ & $\begin{array}{c}\text { Duration/severity } \\
\text { - extreme } \\
\text { - }\end{array}$ \\
\hline Spring & 0.350 & 0.125 & 0.100 \\
\hline Summer & 0.300 & 0.125 & 0.100 \\
\hline Autumn & 0.175 & 0.150 & 0.075 \\
\hline Winter & 0.275 & 0.150 & 0.100 \\
\hline $\begin{array}{c}\text { Zagreb } \\
1992 \text { to } 2018\end{array}$ & $\begin{array}{c}\text { Duration/severity } \\
\text { - mild } \\
-\end{array}$ & $\begin{array}{l}\text { Duration/severity } \\
\text { - moderate }\end{array}$ & $\begin{array}{c}\text { Duration/severity } \\
\text { - extreme } \\
-\end{array}$ \\
\hline$\overline{\text { Spring }}$ & 0.154 & 0.192 & 0.077 \\
\hline Summer & 0.192 & 0.077 & 0.192 \\
\hline Autumn & 0.231 & 0.077 & 0.154 \\
\hline Winter & 0.269 & 0.077 & 0.115 \\
\hline $\begin{array}{c}\text { Split } \\
1951 \text { to } 1991\end{array}$ & $\begin{array}{c}\text { Duration/severity } \\
\text { - mild } \\
-\end{array}$ & $\begin{array}{l}\text { Duration/severity } \\
\text { - moderate }\end{array}$ & $\begin{array}{c}\text { Duration/severity } \\
\text { - extreme } \\
-\end{array}$ \\
\hline Spring & 0.191 & 0.128 & 0.064 \\
\hline Summer & 0.255 & 0.085 & 0.064 \\
\hline Autumn & 0.191 & 0.085 & 0.064 \\
\hline Winter & 0.191 & 0.128 & 0.064 \\
\hline $\begin{array}{c}\text { Split } \\
1992 \text { to } 2018\end{array}$ & $\begin{array}{c}\text { Duration/severity } \\
\text { - mild } \\
-\end{array}$ & $\begin{array}{l}\text { Duration/severity } \\
\text { - moderate }\end{array}$ & $\begin{array}{c}\text { Duration/severity } \\
\text { - extreme } \\
\text { - }\end{array}$ \\
\hline Spring & 0.316 & 0.368 & 0.158 \\
\hline Summer & 0.368 & 0.158 & 0.263 \\
\hline Autumn & 0.263 & 0.316 & 0.211 \\
\hline Winter & 0.316 & 0.368 & 0.158 \\
\hline
\end{tabular}

In the first sub-period, all three stations exhibited the most frequent occurrence of mild droughts. Approximately $30 \%$ of the years had mild drought, which mainly occurred in spring (Zagreb), autumn (Osijek), and summer (Split). In the second sub-period, the frequency of occurrence of moderate and extreme droughts increased in all regions in spring and summer, respectively. This was particularly visible in the Zagreb and Split areas, where the frequency of extreme droughts with a duration of 0-3 months and SPEI sum of $<(-4)$ increased significantly in summer. Of course, this was closely related to the most significant increasing trend of the air temperature in the summer periods in Zagreb and Split (Table 2).

\subsection{PCA}

PCA is generally a very useful tool for the representation of spatially dependent data. There are many examples of the use of this method in the investigation of causal relations between spatial rainfall-runoff and rainfall-drought or drought regionalization [26,27].

As stated previously, the main goal of this study was to define the most important drought indicators in each designated sub-period and the difference in drought occurrence that is evident and related to climate change. These included seasonal precipitation and SPEI decreasing trends, seasonal air temperature increasing trends, and relative frequencies of droughts with a certain duration and severity. The data used in the PCA were the air Tadić, L, Brleković, T, Potočki, K, Leko-Kos, M 
Application of principal component analysis to drought indicators of three representative Croatian regions

temperature, precipitation, and SPEI. The Mann-Kendall statistics $Z_{\mathrm{MK}}$ were calculated on a seasonal basis for the sub-periods previously defined for the three meteorological stations of Osijek, Zagreb, and Split. These variables were the primary variables. The introduction of supplementary variables, such as the probability of drought occurrence with a certain duration and severity, provides a more precise interpretation quality.

\section{RESULTS AND DISCUSSION}

In the previous sections, the described methods were applied to a data series of precipitation, air temperature, and SPEI. Droughts are complex physical processes that are primarily related to precipitation and air temperature and exhibit certain trends over longer time periods. The aim was to answer a certain question by applying PCA, which has been proven as a reliable statistical tool [28]. PCA was applied to two datasets of two recognized sub-periods. The input data presented in Table 2 were the primary data of the Mann-Kendal trend test statistics $Z_{\mathrm{MK}}$. The supplementary dataset consisting of the frequencies of dry years with different severity are presented in Table 3 . The analysis was run for each season separately to detect differences in the drought occurrence and its drivers between the sub-periods.

\subsection{Spring}

The characteristics of the spring period related to drought conditions were analyzed for the two previously recognized sub-periods. The results of the PCA are presented in Figure 4. The principal factor F1 had a dominant impact on the drought indicators during the spring of the first sub-period (69.89\%) (Figure 4a). A combination of the precipitation and air temperature trends, and the frequency of medium drought was exhibited. This variability was essential for the drought characteristics. The second factor, F2, had a contribution of $30.11 \%$ and exhibited a combination of SPEI, and mild and extreme droughts. Zagreb was strongly influenced by the F2 factor, whereas Osijek and Split had more similar features, and they were both influenced by the F1 factor. In the second subperiod, the principal factor $\mathrm{F} 1$ (87.05\%) consisted of all indicators, except for the frequency of extreme droughts belonging to F2. The F2 factor had a contribution of only $12.95 \%$, based on the frequency of severe drought (Figure $4 \mathrm{~b}$ ). The Osijek station was located close to the $\mathrm{x}$-axis, but it did not exhibit any specific dominant variable; even a statistically significant trend of air temperature (Table 2) in combination with other indicators did not appear as dominant. Split exhibited strong domination of the F1 principal factor, which indicated that the variabilities of all indicators made a certain contribution to the drought characteristics. Zagreb was very close to the $y$-axis, indicating a strong influence of the F2 factor, which consisted of only one variable, namely the relative frequency of extreme drought.

a) SPRING - 1st sub-period

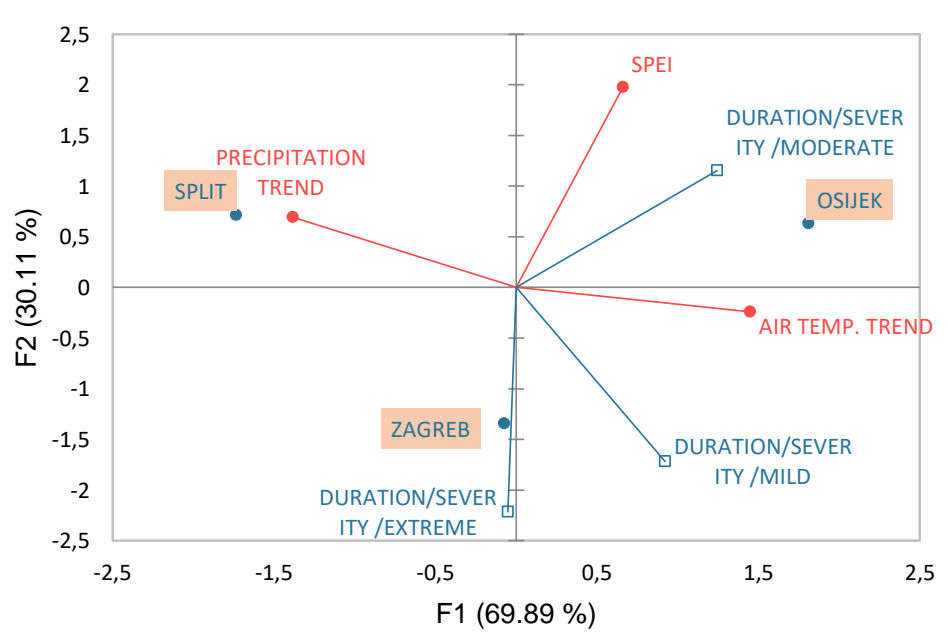

Tadić, L, Brleković, T, Potočki, K, Leko-Kos, M 


\section{b) SPRING - 2nd sub-period}

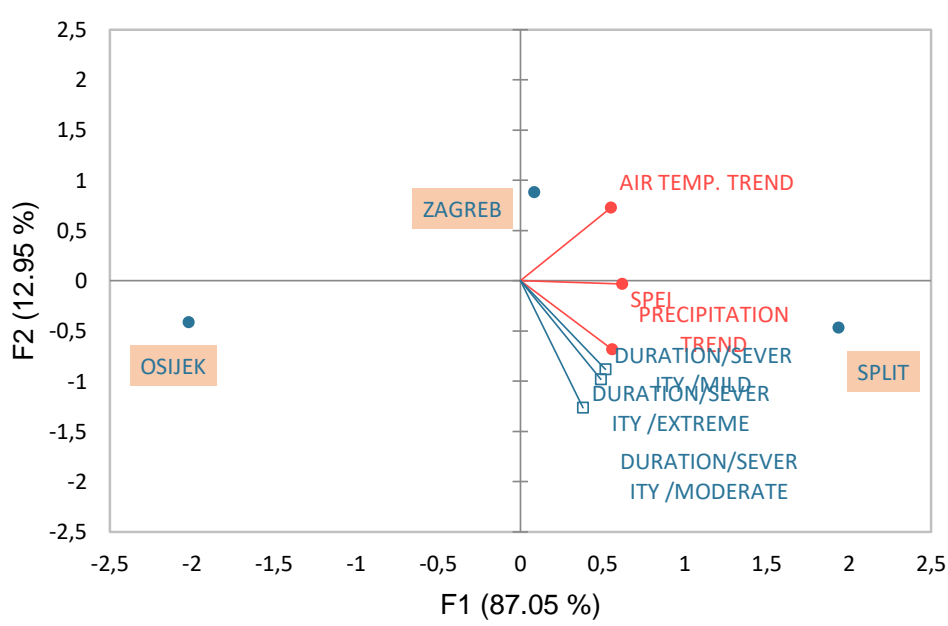

- Active variables • Active observations $\square$ Supplementary variables

Figure 4 PCA of spring in: a) first sub-period; b) second sub-period

\subsection{Summer}

The characteristics of the summer period related to drought conditions were analyzed for the two previously recognized sub-periods. The results of the PCA are presented in Figure 5. The principal factor F1 had a dominant impact on the drought indicators in the summer of the first sub-period (80.5\%) (Figure 5a). It exhibited a combination of all variables (precipitation, air temperature, and SPEI trends). Their variability was important for the Osijek station, whereas the Zagreb station was only weakly influenced by both factors. Factor F2 consisted of supplementary data (frequencies of mild, medium, and extreme droughts). It influenced the drought characteristics of the Split station weakly as defined by the general contribution of the second factor F2 (19.47\%). In the second sub-period, the principal factor F1 consisted of only one variable, namely the air temperature trend, but its contribution was $60.3 \%$. This means that air temperature was an absolutely dominant variable, especially for the Zagreb station, which was supported by the data in Table 2. The F2 factor contributed to all other variables and supplementary data with $39.64 \%$ (Figure $5 \mathrm{~b}$ ). The Split station was dominated by the F2 factor despite a significant increase in the air temperature trend. Osijek was also weakly influenced by F1. The increasing trend of air temperature in the continental part of Croatia in the second sub-period of the Zagreb region (1992 to 2018) and Osijek region (1999 to 2018) became the most important variable in summer. 
a) SUMMER - 1st sub-period

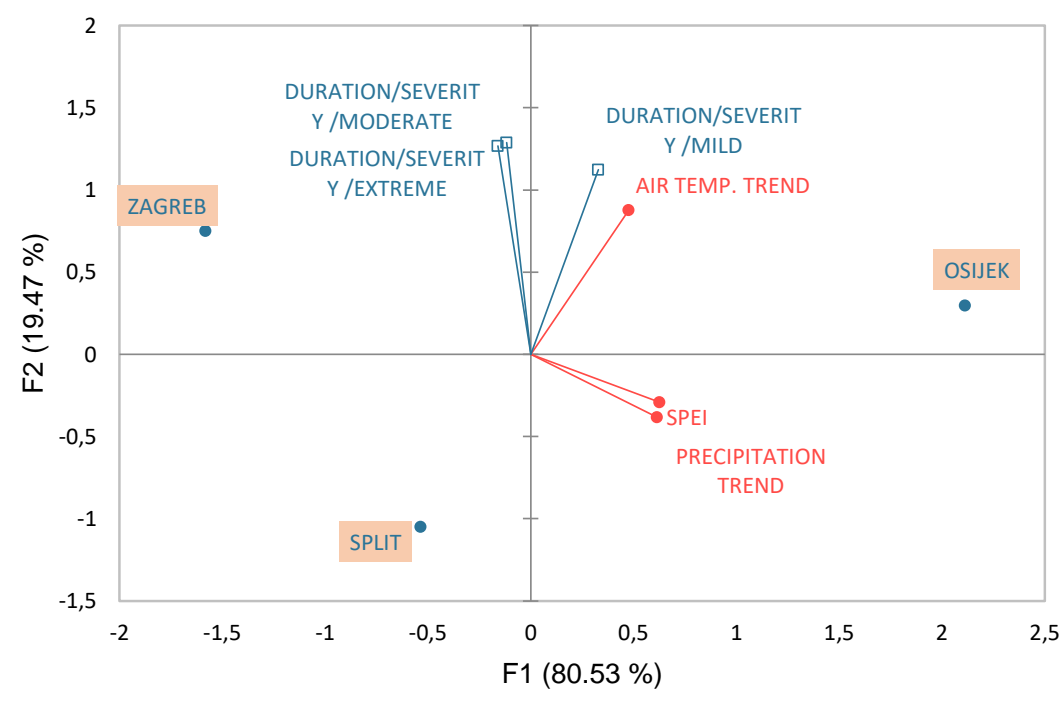

b) SUMMER - 2nd sub-period

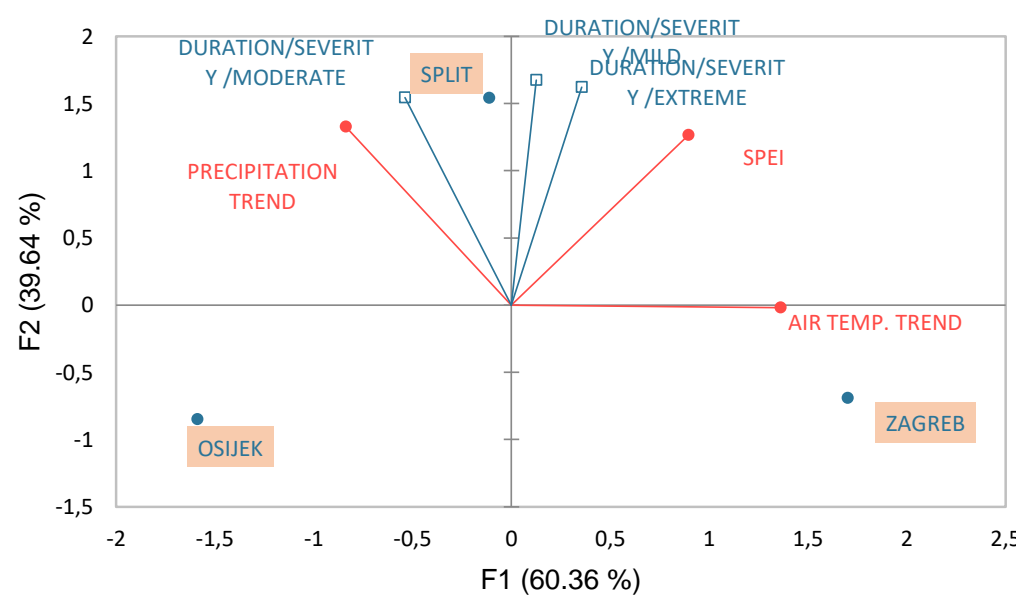

- Active variables - Active observations $\square$ Supplementary variables

Figure 5 PCA of summer in: a) first sub-period; b) second sub-period

\subsection{Autumn}

The characteristics of autumn related to drought conditions were analyzed for the two previously recognized sub-periods. The results of the PCA are presented in Figure 6. The principal factor F1 had a dominant impact on the drought indicators of all three regions in the autumn of the first sub-period, with a significant percentage of $88.3 \%$ (Figure 6a). It exhibited a combination of all variables, except for the frequency of medium droughts. All three stations were influenced by F1, but not very strongly. Osijek had the strongest dominance of F1, which is indicated by its position corresponding to the x-axis. Factor F2 consisted of only one supplementary datum (frequency of medium droughts), with a contribution of only $11.67 \%$. In the second sub-period, the principal factor F1 had a contribution of $66.74 \%$, consisting of the most variables, namely the air temperature and precipitation trends as well as frequencies of mild and extreme droughts. Zagreb was again significantly influenced by the increasing air temperature trends (Figure $6 \mathrm{~b}$ ). Osijek was influenced by F1, but only the occurrence of mild drought was relevant. 
a) AUTUMN - 1st sub-period

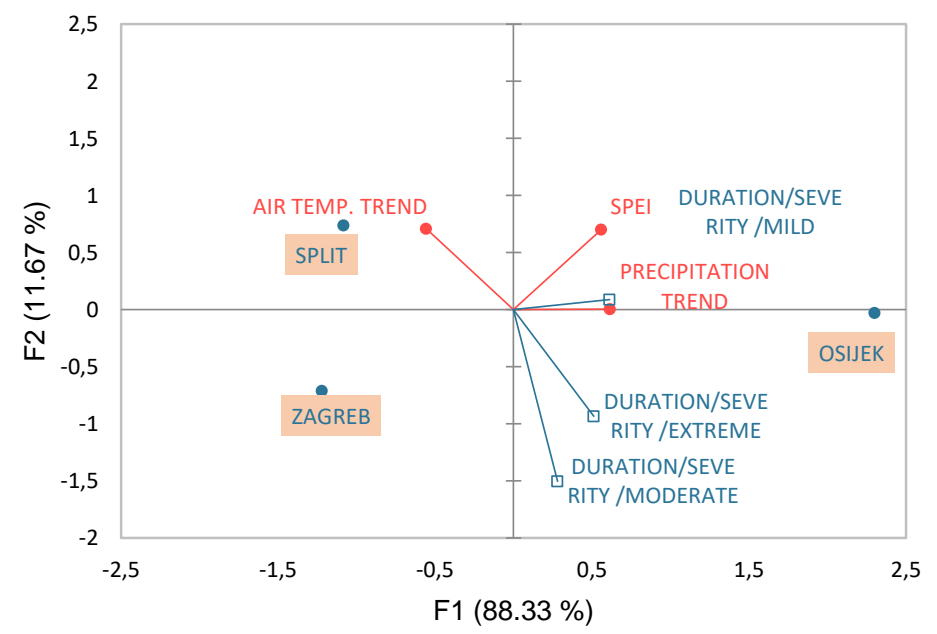

b) AUTUMN - 2nd sub-period

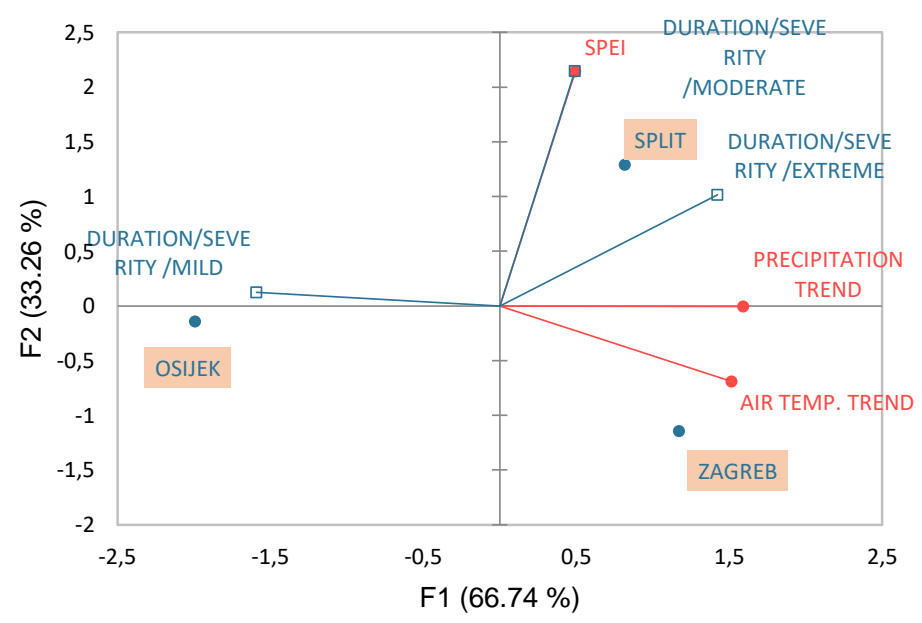

- Active variables • Active observations $\square$ Supplementary variables

Figure 6 PCA of autumn in: a) first sub-period; b) second sub-period

\subsection{Winter}

The drought conditions during winter were analyzed for the two previously recognized sub-periods. The results of the PCA are presented in Figure 7. Compared to other seasons, the winter period exhibited similar impacts of both principal factors. The principal factor F1 (negative precipitation and positive air temperature trends, and frequency of extreme droughts) had an influence of $56.06 \%$. Factor F2 had a contribution of $43.94 \%$, consisting of the SPEI trend, and frequencies of mild and medium drought (Figure 7a). Zagreb was influenced by F1, whereas Osijek and Split were dominated by F2. In the second sub-period, the principal factor F1 had a contribution of $69.84 \%$ and consisted of three variables: increasing air temperature and precipitation trends, and frequency of extreme droughts. Zagreb was weakly influenced by factor F2 (Figure 7b). Osijek was dominated by $\mathrm{F} 1$, but Split exhibited an almost equal impact of factors F1 and F2. 


\section{a) WINTER - 1st sub-period}

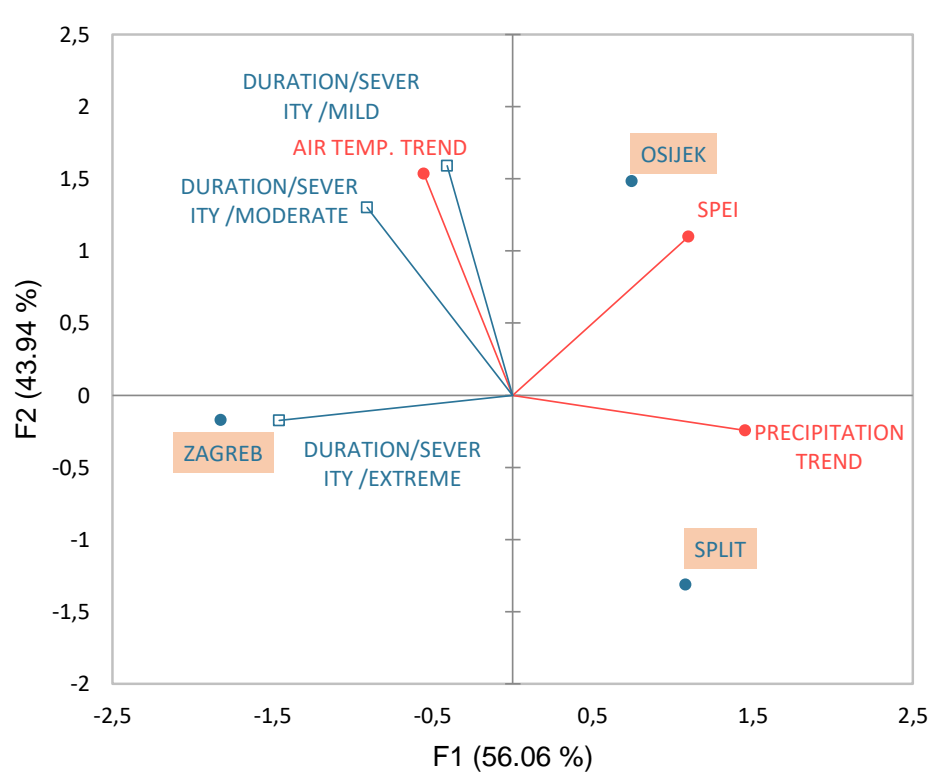

b) WINTER - 2nd sub-period

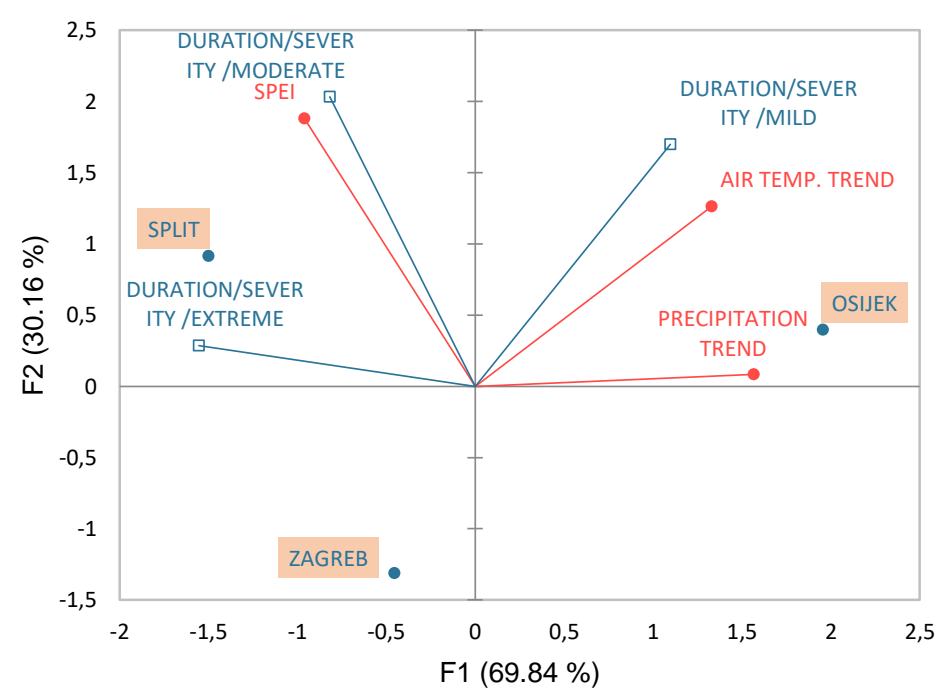

- Active variables - Active observations $\square$ Supplementary variables

\section{Figure 7 PCA of winter in a) first sub-period; b) second sub-period}

\section{CONCLUSIONS}

The previously elaborated matter demonstrated the differences in the drought occurrence and characteristics between the sub-periods 1951 to 1991 (1998) and 1992 (1999) to 2018 on a seasonal basis. The analysis of each station that was representative of a certain region did not lead to firm and strong conclusions. Osijek and Split are cities with completely different climates and exhibited many similarities in the second subperiod, especially in spring and winter. The increasing trends of air temperature and precipitation in spring and winter in the continental part of Croatia (Zagreb and Osijek) had an impact on the basic characteristics of the Tadić, L, Brleković, T, Potočki, K, Leko-Kos, M 
Application of principal component analysis to drought indicators of three representative Croatian regions

continental climate, making them more similar to the characteristics of the Mediterranean climate. The droughts represented by the SPEI exhibited weakening. The summers had almost the same features in both sub-periods. The characteristics of the continental climate in Osijek and Zagreb were still strong, and the increasing trend of air temperature dominated. Changes in the Split region during summer were not very strong, as confirmed by the F2 factor consisting of weak variables. The Zagreb region was strongly influenced by the increasing air temperature in spring, summer, and autumn. These characteristics were the most dominant.

The conclusions presented by Vicente-Serrano et al. [8] and Moberg et al. [29] regarding drought variability and its strong spatial diversity in Europe can also be applied to this region to a certain extent $[10,11]$. Based on this research, more frequent and intense droughts with longer durations can be expected in the Mediterranean region of Croatia in all seasons. In the continental part of the country, severe droughts could have more pronounced seasonality, with prevalence in the summer and winter seasons.

\section{References}

[1] Bonacci, O. 1993: Hydrological Identification of Drought, Hydrological Processes, 7 (3), pp. 249-262. https://doi.org/10.1002/hyp.3360070303

[2] Wanders, N.; van Lannen, H.A.J.; van Loon, A.F. 2010: Indicators for Drought Characterization on a Global Scale, Technical Report No.24.

[3] Bonacci, O. 2010: Analiza nizova srednjih godišnjih temperatura zraka u Hrvatskoj, Građevinar, 62 (9), pp.781-791.

[4] McKee, T.B.; Doeskin, N.J.; Kleist J.1995: Drought Monitoring with Multiple Time Scales, In Proceedings of 9th Conference on Applied Climatology, American Meteorological Society, Boston, USA, pp. 179-184.

[5] Vicente-Serrano, S.M.; Beguaria, S.; López-Moreno, J.I. 2010: A Multiscalar Drought Index Sensitive to Global Warming: The Standardized Precipitation Evapotranspiration Index, Journal of Climate, 23 (7), pp. 1696-1718. https://doi.org/10.1175/2009JCLI2909.1

[6] Spinoni, J.; Vogt, J.V.; Naumann, G.; Barbosa, P.; Dosio, A. 2018: Will drought events become more frequent and severe in Europe?, International Journal of Climatology, 38 (4), pp. 1718-1736. https://doi.org/10.1002/joc.5291

[7] Spinoni, J.; Naumann, G.; Vogt, J.V. 2017: Pan-European seasonal trends and recent changes of drought frequency and severity, Global and Planetary Change, 148, pp. 113-130. https://doi.org/10.1016/i.gloplacha.2016.11.013

[8] Vicente-Serrano, S.M.; Domínguez-Castro, F.; Murphy, C.; Hannaford, J.; Reig, F.; Peña-Angulo, D.; Tramblay, Y.; Trigo, R.M.; et.al. 2021: Long-term variability and trends in meteorological droughts in Western Europe (1851-2018), International Journal of Climatology, 41 (S1), pp. 690-717. https://doi.org/10.1002/joc.6719

[9] Šegota, T.; Filipčić, A. 2003: Köppen's classification of climates and the problem of corresponding Croatian terminology, Geoadria 8 (1), pp. 17-37. https://doi.org/10.15291/geoadria.93

[10] Gajić-Čapka, M.; Cindrić, K.; Pasarić, Z. 2015: Trends in precipitation indices in Croatia, 19612010, Theoretical and Applied Climatology, 121, pp.167-177. https://doi.org/10.1007/s00704-014-1217-9

[11] Perčec Tadić, M.; Gajić-Čapka M.; Zaninović K.; Cindrić K. 2014: Drought Vulnerability in Croatia, Agriculturae Conspectus Scientificus, 79 (1), pp. 31-38.

[12] Tadić, L.; Brleković, T.; Hajdinger, A.; Španja, S. 2019: Analysis of the Inhomogeneous Effect of Different Meteorological Trends on Drought: An Example from Continental Croatia, Water, 11 (12), 2625. https://doi.org/10.3390/w11122625

[13] Liu, X.; Wang, S.; Zhou, Y.; Wang, F.; Li, W.; Liu, W. 2015: Regionalization and Spatiotemporal Variation of Drought in China Based on Standardized Precipitation Evapotranspiration Index (1961-2013), Advances in Meteorology. Article ID 950262. https://doi.org/10.1155/2015/950262

[14] Liu, Y.; Chen, S.; Sun, H.; Gui, D.; Xue, J.; Lei J.; Zeng, X.; Lv, G. 2019: Does the long-term precipitation variations and dry-wet conditions exist inthe arid areas? A case study from China, Quaternary International, 519, pp. 3-9. https://doi.org/10.1016/i.quaint.2019.01.034

[15] Li, B.; Zhou, W.; Zhao, Y.; Ju, Q.; Yu, Z.; Liang, Z.; Acharya, K. 2015: Using the SPEl to Assess Recent Climate Change in the Yarlung Zangbo River Basin, South Tibet, Water, 7 (10), pp. 5474-5486. https://doi.org/10.3390/w7105474 
Application of principal component analysis to drought indicators of three representative Croatian regions

[16] Alexandersson, H. 1986: A Homogeneity Test Applied to Precipitation Data, Journal of Climatology, 6 (6), pp. 661-675. https://doi.org/10.1002/joc.3370060607

[17] Pandžić, K.; Kobold, M.; Oskoruš, D.; Biondić, B.; Biondić, R.; Bonacci, O. et al. 2020: Standard normal homogeneity test as a tool to detect change points in climate-related river discharge variation: case study of the Kupa River Basin, Hydrological Sciences Journal, 65 (2), pp. 227-241. https://doi.org/10.1080/02626667.2019.1686507

[18] Ming Kang, H.; Yusof , F. 2012: Homogeneity Tests on Daily Rainfall Series in Peninsular Malaysia, International Journal of Contemporary Mathematical Sciences, 7 (1), pp. $9-22$.

[19] Ahmed, K.; Shahid, S.; Ismail, T.; Nawaz, N.; Wang, X-J. 2018: Absolute homogeneity assessment of precipitation time series in an arid region of Pakistan, Atmósfera, 31 (3), pp. 301-316. https://doi.org/10.20937/atm.2018.31.03.06

[20] Mann, H.B. 1945: Nonparametric tests against trend, Econometrica: Journal of the econometric society, 13 (3), pp. 245-259. https://doi.org/10.2307/1907187

[21] Kendall, M.G. 1948: Rank Correlation Methods, Charles Griffin \& Company Limited, London, UK.

[22] Gilbert, R.O. 1987: Statistical Methods for Environmental Pollution Monitoring, Wiley, New York, USA.

[23] Asfaw, A.; Simane, B.; Hassen, A.; Bantider, A. 2018: Variability and time series trend analysis of rainfall and temperature in northcentral Ethiopia: A case study in Woleka sub-basin, Weather and Climate Extremes, 19, pp. 29-41. https://doi.org/10.1016/j.wace.2017.12.002

[24] Salmi, T.; Määttä, A.; Anttila, P.; Ruoho-Airola, T.; Amnell, T. 2002: Detecting trends of annual values of atmospheric pollutants by the Mann-Kendall test and Sen's slope estimates -the Excel template application MAKESENS. Publications on Air Quality 2002, 31, Finnish Meteorological Institute, Helsinki.

[25] Wang, F.; Wang, Z.; Yang, H.; Zhao, Y.; Zhang, Z.; Li, Z.; Hussain, Z. 2019: Copula-Based Drought Analysis Using Standardized Precipitation Evapotranspiration Index: A Case Study in the Yellow River Basin, China, Water, 11 (6), 1298. https://doi.org/10.3390/w11061298

[26] Rao, A.R.; Burke, T.T. 1997: Principal Component Analysis of Hydrologic Data. In: Harmancioglu, N.B.; Alpaslan, M.N.; Ozkul, S.D.; Singh, V.P. (Eds.) Integrated Approach to Environmental Data Management Systems. NATO ASI Series, Series 2: Environment, vol 31. https://doi.org/10.1007/978-94-011-5616-5_24

[27] Gocic, M.; Trajkovic, S. 2014: Spatiotemporal characteristics of drought in Serbia, Journal of Hydrology, 510, pp. 110-123. https://doi.org/10.1016/i.jhydrol.2013.12.030

[28] Tadić, L.; Bonacci, O.; Brleković, T. 2019: An example of principal component analysis application on climate change assessment, Theoretical and Applied Climatology, 138, pp. 1049-1062. https://doi.org/10.1007/s00704-019-02887-9

[29] Moberg, A. et al. 2006: Indices for daily temperature and precipitation extremes in Europe analyzed for the period 1901-2000, Journal of Geophysical Research: Atmospheres, 111 (D2).

https://doi.org/10.1029/2006JD007103

Please cite this article as: Tadić, L.; Brleković, T.; Potočki, K.; Leko-Kos, M.: Application of principal component analysis to drought indicators of three representative Croatian regions, Electronic Journal of the Faculty of Civil Engineering Osijek-e-GFOS, 2021, 22, pp. 41-55, https://doi.org/10.13167/2021.22.4 